Meyneld, G. G. (1957). J. gen. Microbiol. 16, 396-404

\title{
The Applicability of the Hypothesis of Independent Action to Fatal Infections in Mice given Salmonella typhimurium by Mouth
}

\author{
By G. G. MEYNELL
}

Departments of Bacteriology, London School of Hygiene and Tropical Medicine, and the Postgraduate Medical School of London, * Ducane Road, London, W. 12

SUMMARY: Mice were challenged by mouth with a suspension containing equal numbers of streptomycin-sensitive (Str-) and streptomycin-resistant $\left(\mathrm{Str}^{+}\right)$variants of Salmonella typhimurium. These variants were of equal virulence but the $\mathrm{Str}^{+}$ variant grew more slowly in vivo than the Str- variant. The LD50 dose contained c. $5 \times 10^{5}$ bacteria. Heart blood obtained from mice dying from many LD50 doses nearly always contained a great excess of the Str ${ }^{-}$variant, but blood from mice dying from less than one LD 50 dose contained either $\mathrm{Str}^{-}$, $\mathrm{Str}^{+}$, or a mixture of Str and $\mathrm{Str}^{+}$variants. The appearance of the $\mathrm{Str}^{+}$variant alone in the latter mice strongly suggests that these fatal infections were initiated by a very small number of organisms or possibly by a single organism. It is therefore concluded that these organisms were acting independently. In this system, it is likely that any bacterium which enters the tissues from the gut can initiate a fatal infection and that the probability of effecting such an entrance almost entirely determines the probability of an inoculated bacterium causing a fatal infection.

The inoculation of a partially resistant host with many bacteria will often cause a fatal infection when the inoculation of one bacterium is very unlikely to do so. Of several hypotheses advanced to account for this phenomenon, the most satisfactory appears to be that described elsewhere (Meynell \& Stocker, 1957) as the 'hypothesis of independent action' which postulates $(a)$ that bacteria act independently after inoculation, and $(b)$ a mean probability $(1>p>0)$ per inoculated bacterium of initiating a fatal infection which is constant and unaffected by the number of bacteria inoculated. On this hypothesis therefore, there will always be a chance that the death of a host inoculated with many bacteria will be caused by the progeny of only one of the inoculated bacteria. Although many of the inoculated bacteria may multiply to some extent, the total toxic effect of their clones will never be fatal and will be negligible compared to the toxic effect of the clone descended from only one of the inoculated bacteria. The progenitor of this clone may thus be said to have initiated the fatal infection.

A well-known alternative hypothesis is that of the minimal lethal dose which postulates that if the dose exceeds a critical minimum size, death is inevitable; while if it is smaller than the minimum, the host is certain to survive. Thus, a lethal dose might be supposed to saturate the host defences so that death follows the multiplication either of all the inoculated bacteria or of those bacteria not needed for saturation. In the latter case, a fatal infection could

* Present address. 
be initiated by one organism on the rare occasion when the inoculated dose exceeded the minimal lethal dose by precisely one organism. This event is clearly very unlikely. Hence, if the hypothesis of the minimal lethal dose is valid, many bacteria will initiate each fatal infection as a result of their cooperative action on the host.

The following test should distinguish these hypotheses (Kunkel, 1934). A suspension is prepared which contains equal proportions of recognizable variants of the chosen pathogen, each variant being distinguished only by a marker character unrelated to its virulence. A series of challenge doses is prepared from this suspension in which the most potent dose contains many LD 50 doses and the least potent, only a fraction of one LD50 dose. These doses are administered to groups of hosts. Any hosts which die are sampled to determine the composition of the bacterial population responsible for death. Any host in which a fatal infection was initiated by one bacterium should contain a great preponderance, if not a pure culture, of only one variant. It can be shown (Meynell \& Stocker, 1957) that where the hypothesis of independent action is applicable, most fatal infections following the inoculation of one or less than one LD50 dose are initiated by a single organism if the hosts do not differ in resistance. When the hosts vary in resistance, as is probably always the case, one can only say that the chance that a given death was due to the multiplication of one bacterium is inversely proportional to the size of the dose. It follows that if the hypothesis of independent action is valid, most hosts dying after challenge by small or large doses should yield respectively either one variant, alone or predominantly, or all the variants. But if the hypothesis of the minimal lethal dose is valid, all fatal infections are initiated by many bacteria and hence each fatally infected host should yield all the variants.

The LD50 dose of Salmonella typhimurium, when given by mouth to mice, is $5 \times 10^{5}$ organisms. The possibility that the hypothesis of independent action applied to this system has been tested by giving mice by mouth a mixture of streptomycin-sensitive (Str-) and streptomycin-resistant $\left(\mathrm{Str}^{+}\right)$variants of this organism. The composition of the bacterial population responsible for death was determined by examination of samples of heart blood removed post mortem. The predictions have to be modified for this system for although, as will be shown, both variants are about equal in virulence, the Str $^{-}$variant grows more rapidly than the $\mathrm{Str}^{+}$variant so that any mouse in which a fatal infection is initiated by both variants will probably yield at least a preponderance of the Str- variant post mortem.

The results indicate that the inoculated bacteria act independently, not cooperatively. Other evidence suggests that nearly every organism which passes from the gut to the tissues is capable of initiating a fatal infection. The experiment with mixed inocula therefore also shows that the bacteria are independent during their passage from the gut lumen. 


\section{METHODS}

Bacteria. A streptomycin-sensitive strain of Salmonella typhimurium, designated GLeB, was isolated from a sick mouse and passaged several times by intraperitoneal injection. After the last passage, a streptomycin-resistant variant was isolated by inoculating plates of nutrient agar containing $200 \mu \mathrm{g}$. streptomycin $/ \mathrm{ml}$. with a heavy suspension of the passaged strain. Both strains were preserved by freeze-drying. The $\mathrm{Str}^{+}$strain, also used by Meynell (1955), has the same efficiency of plating on streptomycin agar as on nutrient agar.

Challenge doses were prepared by mixing equal volumes of three overnight broth cultures of each variant inoculated from the dried stock cultures. The mixture was diluted as necessary in quarter-strength Ringer's solution.

Inoculations. All mice were kept without food, water or sawdust for $18 \mathrm{hr}$. before challenge by mouth: those challenged by intraperitoneal injection were kept under normal conditions throughout. In the first experiment, each mouse was infected by mouth by placing $0 \cdot 2 \mathrm{ml}$. suspension in the end of a drinking tube suspended from the cage lid. This was usually taken within $20 \mathrm{~min}$. In the other experiments each mouse was given $0.2 \mathrm{ml}$. of suspension through a polythene catheter passed beyond the mid-point of the oesophagus.

Mice. Webster BSVS mice were used in Exp. 1 and for the titrations of the Str- variant, and were kept in individual pots. The other experiments were performed on the stock mice of the Postgraduate Medical School which were kept in large glass pots in groups of 10.

Examination of the post mortem heart blood. Heart blood was removed from each mouse post mortem and added to $5 \mathrm{ml}$. digest broth which was thereafter stored at $4^{\circ}$. Portions of the diluted blood were plated by loop in a standard manner on nutrient agar and on streptomycin agar $(200 \mu \mathrm{g} . / \mathrm{ml}$. agar $)$. Control experiments showed that when the Str ${ }^{+}$variant formed less than $10 \%$ of the total population, the number of colonies on streptomycin agar was much less than on nutrient agar. When the $\operatorname{Str}^{+}$variant formed more than $10 \%$ of the population, separate colonies were scored by subculture from nutrient agar to streptomycin agar.

\section{RESULTS}

\section{The response of mice to challenge by the Str-variant}

When groups of mice were challenged by mouth with serial tenfold dilutions of the Str- $^{-}$variant, the proportion of mice dying never increased steadily with increase in dosage and inversions in the sequence were always present (Table 1). The slope of the dose-response curve (estimated graphically on a log-dose/probit-mortality plot) was about $\mathbf{0 \cdot 7}$, which was markedly less than the maximum slope of $\mathbf{2 \cdot 0 0}$ predicted for infective systems by the hypothesis of independent action (Meynell \& Stocker, 1957). This observation showed that the resistances of individual mice differed considerably and that it was therefore impossible to predict exactly either the mean probability of an inoculated organism causing a fatal infection or the probability that a given fatal infec- 
tion was initiated by one bacterium. The former probability was clearly small since the LD 50 dose of the Str- variant when given by mouth was $c .5 \times 10^{5}$ bacteria. It will be shown below that the variants are approximately equal in virulence in Expts. 1 and 3 and probably also in Expt. 2. Mice always responded far more uniformly to the Str- variant when given by intraperitoneal injection (Table 1); the LD 50 dose was $c .2 \cdot 5$ organisms by this route.

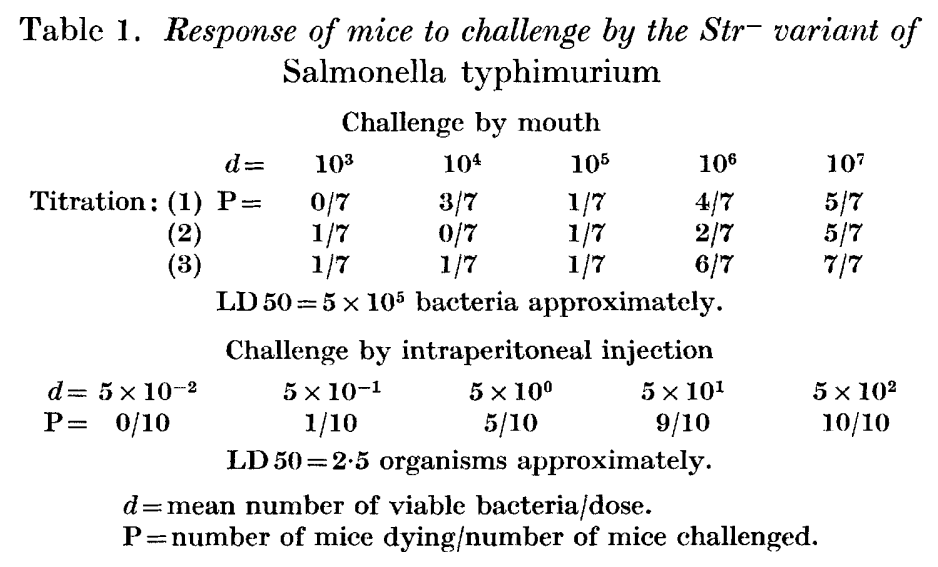

\section{The proportions of the Str- and Str+ variants present in heart blood obtained post mortem from mice challenged with a mixture of both variants}

Expt. 1. The results are shown in Table 2 which gives the dose and route of inoculation for each group of mice; the proportion of mice dying; the proportion of each variant present in the challenge dose and in the heart blood samples with the number of colonies scored; and the number of days each mouse survived after challenge. It can be seen that the heart blood of all mice dying after challenge by many LD 50 doses, given either by mouth or by intraperitoneal injection, contained a great preponderance of the $\mathrm{Str}^{-}$variant. These observations clearly showed that the $\mathrm{Str}^{-}$variant outstripped the $\mathrm{Str}^{+}$variant in vivo. Therefore, if every fatal infection resulted from the multiplication of a number of bacteria drawn at random from the challenge dose, and never from one bacterium as postulated by the hypothesis of independent action, it would be expected that the $\mathrm{Str}^{-}$variant would always predominate in the heart post mortem. The third part of Table 2 shows that this result was not obtained since $3 / 8$ mice dying from a dose of $10^{4}$ bacteria ( 0.02 LD 50 dose) yielded only the $\mathrm{Str}^{+}$variant. Two other mice yielded a mixture containing a preponderance of the $\operatorname{Str}^{-}$variant, such as would be expected if either one or many bacteria of each kind initiated these fatal infections. Three mice yielded only the Strvariant; their deaths may have been due to $\mathrm{Str}^{-}$bacteria only but alternatively, any contributing $\mathrm{Str}^{+}$bacteria might have been outgrown and might not have entered the heart blood by the time death occurred.

Expt. 2. This experiment was designed to show that the appearance of the $\mathrm{Str}^{+}$variant alone in 3/8 mice dying from 0.02 LD50 dose in Expt. 1 was not due to selection of $\mathrm{Str}^{+}$organisms of greater virulence or growth rate than the 
Table 2. The proportions of Str- and Str ${ }^{+}$variants of Salmonella typhimurium present in the post mortem heart blood of mice challenged by both variants (Expt. 1)

\begin{tabular}{|c|c|c|c|c|c|c|}
\hline \multirow[b]{2}{*}{$\begin{array}{c}\text { Route of } \\
\text { inoculation }\end{array}$} & \multirow[b]{2}{*}{$\begin{array}{l}\text { Dose and } \\
\text { mortality }\end{array}$} & \multirow[b]{2}{*}{ Sample } & \multicolumn{2}{|c|}{$\begin{array}{l}\text { Proportion of } \\
\text { each variant }\end{array}$} & \multirow[b]{2}{*}{$\begin{array}{l}\text { No. } \\
\text { colonies } \\
\text { scored }\end{array}$} & \multirow[b]{2}{*}{$\begin{array}{c}\text { Survival } \\
\text { period } \\
\text { (days) }\end{array}$} \\
\hline & & & $\begin{array}{l}\text { Str }^{-} \\
\text {variant }\end{array}$ & $\begin{array}{c}\text { Str }^{+} \\
\text {variant }\end{array}$ & & \\
\hline - & - & Challenge dose & 0.57 & $0 \cdot 43$ & 180 & - \\
\hline Oral & $\begin{array}{l}10^{7} \text { organisms } \\
(20 \text { LD 50 doses }) \\
5 / 5 \text { died }\end{array}$ & $\begin{array}{l}\text { Post mortem } \\
\text { heart blood }\end{array}$ & $\begin{array}{l}0.997 \\
0.999 \\
0.975 \\
0.896 \\
0.999\end{array}$ & $\begin{array}{l}0.003 \\
0 \cdot 001 \\
0 \cdot 025 \\
0 \cdot 104 \\
0 \cdot 001\end{array}$ & $\begin{array}{c}8 \times 10^{3} \\
10^{4} \\
600 \\
73 \\
10^{4}\end{array}$ & $\begin{array}{l}6 \\
5 \\
9 \\
6 \\
8\end{array}$ \\
\hline $\begin{array}{l}\text { Intra- } \\
\text { peritoneal }\end{array}$ & $\begin{array}{l}2.5 \times 10^{4} \text { organ- } \\
\text { isms }\left(10^{4} \text { LD } 50\right. \\
\text { doses }) \\
5 / 5 \text { died }\end{array}$ & $\begin{array}{c}\text { Post mortem } \\
\text { heart blood }\end{array}$ & $\begin{array}{l}0.993 \\
0.983 \\
0.959 \\
0.836 \\
0.984\end{array}$ & $\begin{array}{l}0 \cdot 007 \\
0 \cdot 017 \\
0 \cdot 041 \\
0 \cdot 164 \\
0 \cdot 016\end{array}$ & $\begin{array}{c}5 \cdot 3 \times 10^{3} \\
460 \\
197 \\
116 \\
181\end{array}$ & $\begin{array}{l}6 \\
7 \\
5 \\
5 \\
6\end{array}$ \\
\hline Oral & $\begin{array}{l}10^{4} \text { organisms } \\
(0 \cdot 02 \text { LD 50 } \\
\text { doses }) \\
\text { 10/48 died; } \\
8 \text { scored }\end{array}$ & $\begin{array}{c}\text { Post mortem } \\
\text { heart blood }\end{array}$ & $\begin{array}{l}0 \\
0 \\
0 \\
1 \cdot 0 \\
1 \cdot 0 \\
1 \cdot 0 \\
0 \cdot 993 \\
0.99\end{array}$ & $\begin{array}{l}1 \cdot 0 \\
1 \cdot 0 \\
1 \cdot 0 \\
0 \\
0 \\
0 \\
0.007 \\
0 \cdot 01\end{array}$ & $\begin{array}{c}310 \\
78 \\
27 \\
10^{7} \\
4.4 \times 10^{4} \\
3 \times 10^{3} \\
10^{3} \\
1.5 \times 10^{3}\end{array}$ & $\begin{array}{r}15 \\
21 \\
15 \\
10 \\
11 \\
7 \\
10\end{array}$ \\
\hline
\end{tabular}

original $\mathrm{Str}^{-}$variant. The challenge dose was therefore prepared from the $\mathrm{Str}^{+}$ present alone in one of the mice in Expt. 1 and the stock strain of the Strvariant. The proportion of the latter in the dose was 0.59 (98 colonies scored). Four out of sixteen mice and 5/60 mice died from doses of $5 \times 10^{7}$ organisms (20 LD50 doses) and $5 \times 10^{4}$ organisms (0.1 LD50 dose), respectively. The heart blood samples obtained post mortem from all save one of these mice contained the Str ${ }^{-}$variant either alone or with a very small proportion of the Str+ variant $(<0.01)$; the proportion of the $\mathrm{Str}^{-}$variant in the exceptional sample was $\mathbf{0} \cdot \mathbf{2}$. More than $10^{4}$ colonies were scored from each mouse.

This result strongly suggested that the predominance of the $\mathrm{Str}^{+}$variant in 3/8 mice dying in Expt. 1 was not a consequence of mutation to greater virulence or growth rate. So few mice died from the smaller dose that the absence of mice yielding the $\mathrm{Str}^{+}$variant alone is without significance.

Expt. 3. The results are given in Table 3 and resemble those of Expt. 1. One mouse, possibly of unusually high resistance, yielded the $\mathrm{Str}^{+}$variant alone after challenge by $1.25 \times 10^{8}$ bacteria ( 250 LD 50 doses), the other eleven mice in this group all yielding the $\mathrm{Str}^{-}$variant either alone or in a marked excess. Twenty-one mice died from a dose of $1.25 \times 10^{5}$ bacteria ( 0.25 LD50 dose); the $\operatorname{Str}^{+}$variant was recovered alone from 4/16 mice examined. Ten of the remaining mice yielded only the $\operatorname{Str}^{-}$variant and two yielded both variants.

Expt. 4. The challenge dose was prepared from a strain of the $\mathrm{Str}^{+}$variant isolated in pure culture from a mouse in Expt. 3, mixed with the stock strain of

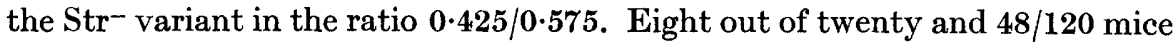


died from doses of $5 \times 10^{7}$ bacteria (100 LD50 doses) and $5 \times 10^{4}$ bacteria (0.1 LD50 dose), respectively. All mice yielded the Str ${ }^{-}$variant alone, Str ${ }^{+}$ organisms were not isolated from any mice.

Table 3. The proportions of Str- and Str ${ }^{+}$variants of Salmonella typhimurium present in the post mortem heart blood of mice challenged by mouth by both variants (Expt. 3)

\begin{tabular}{|c|c|c|c|c|c|}
\hline \multirow[b]{2}{*}{ Dose and mortality } & \multirow[b]{2}{*}{ Sample } & \multicolumn{2}{|c|}{$\begin{array}{l}\text { Proportion of } \\
\text { each variant }\end{array}$} & \multirow{2}{*}{$\begin{array}{l}\text { No. } \\
\text { colonies } \\
\text { scored }\end{array}$} & \multirow{2}{*}{$\begin{array}{c}\text { Surviva } \\
\text { period } \\
\text { (days) }\end{array}$} \\
\hline & & $\begin{array}{c}\text { Str }^{-} \\
\text {variant }\end{array}$ & $\begin{array}{c}\operatorname{Str}^{+} \\
\text {variant }\end{array}$ & & \\
\hline 一 & Challenge dose & $0 \cdot 66$ & $0 \cdot 34$ & 76 & 一 \\
\hline $1.25 \times 10^{8}$ organisms & Post mortem & 0 & $1 \cdot 0$ & 148 & 9 \\
\hline (250 LD 50 doses) & heart blood & $1 \cdot 0$ & 0 & $10^{2}-10^{3}$ & 6 \\
\hline $17 / 19$ died; & & $1 \cdot 0$ & 0 & 33 & 8 \\
\hline 12 scored & & 1.0 & 0 & c. $10^{3}$ & 8 \\
\hline & & $1 \cdot 0$ & $\mathbf{0}$ & c. $10^{2}$ & 9 \\
\hline & & $1 \cdot 0$ & $\mathbf{0}$ & c. $10^{3}$ & 9 \\
\hline & & $1 \cdot 0$ & $\mathbf{0}$ & c. $10^{5}$ & 9 \\
\hline & & 0.92 & $0 \cdot 08$ & 80 & $\mathbf{5}$ \\
\hline & & 0.94 & $0 \cdot 06$ & 34 & $\mathbf{5}$ \\
\hline & & 0.96 & $0 \cdot 04$ & 81 & 6 \\
\hline & & 0.96 & $0 \cdot 05$ & 27 & 8 \\
\hline & & 0.9 & $0 \cdot 1$ & c. $10^{2}$ & 8 \\
\hline $\mathbf{1 . 2 5} \times 10^{5}$ organisms & Post mortem & 0 & $1 \cdot 0$ & 177 & 6 \\
\hline (0.25 LD 50 doses) & heart blood & 0 & $1 \cdot 0$ & 217 & 9 \\
\hline 21/140 died; & & $\mathbf{0}$ & $1 \cdot 0$ & 101 & 13 \\
\hline 16 scored & & 0 & $1 \cdot 0$ & 90 & 13 \\
\hline & & $1 \cdot 0$ & 0 & c. $10^{2}$ & 5 \\
\hline & & $1 \cdot 0$ & 0 & c. $10^{2}$ & 6 \\
\hline & & $1 \cdot 0$ & o & 36 & 6 \\
\hline & & $1 \cdot 0$ & 0 & 24 & 7 \\
\hline & & $1 \cdot 0$ & 0 & c. $10^{3}$ & 8 \\
\hline & & $1 \cdot 0$ & 0 & c. $10^{3}$ & 9 \\
\hline & & 1.0 & 0 & c. $10^{2}$ & 9 \\
\hline & & $1 \cdot 0$ & 0 & $10^{2}-10^{3}$ & 9 \\
\hline & & $1 \cdot 0$ & 0 & c. $10^{3}$ & 9 \\
\hline & & $1 \cdot 0$ & $\mathbf{0}$ & c. $10^{3}$ & 11 \\
\hline & & 0.96 & 0.04 & 45 & 9 \\
\hline & & 0.83 & $0 \cdot 17$ & 71 & 6 \\
\hline
\end{tabular}

Other experiments. In earlier experiments, mice were challenged by mouth with $10^{4}$ bacteria $(0.02$ LD 50 dose) of a suspension containing a proportion of $\mathbf{0 . 6 4}$ of the Str $^{-}$variant. Four days later the mice were killed and the bacterial population of the mesenteric glands examined. The $\mathrm{Str}^{+}$variant was isolated alone from two glands, the $\mathrm{Str}^{-}$variant alone being isolated from the other ten glands which yielded salmonellas.

\section{DISCUSSION}

Fatal infections following the inoculation of many LD50 doses of a mixture of equally virulent $\mathrm{Str}^{-}$and $\mathrm{Str}^{+}$variants of Salmonella typhimurium are assumed to be initiated by both $\mathrm{Str}^{-}$and $\mathrm{Str}^{+}$bacteria, whichever hypothesis 
is valid. Nevertheless, the post-mortem heart blood of all, save one, of the mice dying after challenge by such doses contained an excess, if not a pure culture, of the $\mathrm{Str}^{-}$variant. It may therefore be concluded that when a fatal infection is initiated by a mixture of $\mathrm{Str}^{-}$and $\mathrm{Str}^{+}$bacteria, as would always be the case if the hypothesis of the minimal lethal dose were generally valid, Str- bacteria should predominate in the heart blood at post mortem.

Many mice which died from less than one LD50 dose yielded only the Str ${ }^{+}$ variant. Hence, the bacteria which initiated the fatal infection in these mice must all have been $\mathrm{Str}^{+}$and their number must have been quite small (say, less than 10), or else at least one $\mathbf{S t r}^{-}$bacterium would have been included and its progeny would have been present in the heart blood post mortem. It seems implausible to suggest that a fatal infection can only be initiated by the cooperation of such a small number of bacteria, so that it seems justifiable to conclude that it could have been initiated by only one bacterium. This implies that the bacteria were acting independently as postulated by the hypothesis of independent action, which therefore applies to this system. As indicated in the introduction, this result is very unlikely to be obtained if the hypothesis of the minimal lethal dose be valid.

The proportion of one variant in the challenge dose in Expts. 1 and 3 was approximately equal to the proportion of mice which yielded a pure culture of that variant following challenge by less than one LD 50 dose, showing that the mean probability of an inoculated bacterium causing a fatal infection was about the same for each variant (i.e. that the variants were probably equal in virulence). This conclusion could have been further tested by determining the LD 50 dose for each variant separately, but titrations using moderate numbers of mice would have detected only extreme differences in virulence because of the presence of gross variation in host resistances (Table 1).

Since both variants were about equal in virulence, the $\mathrm{Str}^{-}$variant must have outstripped the $\mathrm{Str}^{+}$in vivo, just as it can be shown to do in vitro, owing to its more rapid rate of growth. It is therefore not surprising that mice whose deaths were due to $\mathrm{Str}^{+}$bacteria only, survived longer than those which yielded Str- bacteria only (Tables 2 and 3). The difference in survival times may have been greater than the tabulated results suggest, for Expts. 1 and 3 were ended after 3 and 2 weeks, respectively, and some late deaths may have been missed.

Expt. 4 differed from the previous experiments in that no fatally infected mice yielded any $\mathrm{Str}^{+}$bacteria in their heart blood. It is unlikely that the virulence or the growth rates of the variants had altered owing to genotypic changes and other experiments suggest that such alterations may be phenotypic in origin. For example, on one occasion, the strains used in Expt. 1 were mixed in equal parts and $10^{5} \mathrm{LD} 50$ doses inoculated by intraperitoneal injection. At post mortem, an unusually high proportion $(c .0 \cdot 3)$ of the bacteria in the heart blood were $\mathrm{Str}^{+}$. Alterations of this sort might invalidate experiments intended to show that mutation to greater virulence, etc., was not responsible for the occurrence of the $\mathrm{Str}^{+}$variant alone in the heart blood of some mice. However, the validity of Expt. 2 is unaffected, since mice challenged by many LD 50 doses responded in the same way as those in Expts. 1 and $\mathbf{3}$. 
The question then arises as to why only a few, or possibly only one, of the inoculated organisms were able to multiply to a fatal extent when the rest could not. It will be noted that the experiment with mixed inocula does not provide an answer, for it can only estimate the number of bacteria which initiate each fatal infection. The following three expcriments suggest that in this system the bacteria initiating fatal infections may have been the only bacteria which passed from the gut to the tissues where they were of maximal virulence: $(a)$ the resistance of mice to oral infection by the Str ${ }^{+}$variant is greatly lowered when the normal gut flora is previously altered by giving streptomycin by mouth (Bohnhoff, Drake \& Miller, 1954; Meynell, 1955). The LD50 dose of the $\mathrm{Str}^{+}$variant of Salmonella typhimurium was decreased in this way from c. $5 \times 10^{5}$ to 1.2 organisms. Unless streptomycin affects the state of the gut secretions, this observation shows that the small probability of an inoculated organism causing a fatal infection is not due to most of the dose being killed within the gut lumen; (b) Meynell \& Stocker (1957) inoculated mice with a mixture of two variants of $S$. typhimurium by intraperitoneal injection. The post mortem heart blood did not usually contain only one variant after administration of $0 \cdot 2 \mathrm{LD} 50$ dose (200 bacteria), as predicted by the hypothesis of independent action. Instead, only a marked predominance of one variant or the other was found. (The presence of the lesser proportion was ascribed to the effects of a terminal breakdown in resistance which allowed bacteria to multiply which otherwise would have been restrained by the host defences.) Since many pure infections by the slow-growing $\mathrm{Str}^{+}$variant were observed after challenge by mouth, it seems likely that the number of bacteria which entered the tissues from the gut was less than 200, the number inoculated in the earlier experiments; $(c)$ the entry of one bacterium might always be fatal in this system, for the Str $^{-}$variant is very virulent by intraperitoneal injection (Table 1). However, this argument may be misleading since the virulence of S. typhimurium is greatly affected by the route of inoculation (Dutton, 1955).

The present experiments resemble those performed by Liu \& Henle (1953) with a mixture of influenza $A$ and $B$ viruses inoculated into the allantoic cavity of the chick embryo, a system to which either hypothesis might conceivably apply since the ID50 dose contains $c .10$ virus particles (Donald \& Isaacs, 1954). When $10^{3}$ ID 50 doses or less are inoculated, influenza B grows more slowly than influenza A (Liu \& Henle, 1951) so that these viruses can be likened to the $\mathrm{Str}^{+}$and $\mathrm{Str}^{-}$variants respectively. Eggs receiving $10^{3}$ ID 50 doses (Liu \& Henle, 1951) or 32 ID 50 doses (Liu \& Henle, 1953) of a mixture containing equal numbers of ID 50 doses of each virus therefore yielded an excess of influenza A after incubation. Yet eggs inoculated with < 16 ID50 doses sometimes yielded an excess of influenza $\mathbf{B}$ with a small proportion of influenza A. This finding, like the occurrence of mice yielding only the Str ${ }^{+}$ variant, is most simply explained on the assumption that inoculated particles act independently in the early stages of infection. The presence of the small proportion of influenza $\mathbf{A}$ in the eggs containing a majority of influenza $\mathbf{B}$ may be ascribed to a breakdown in resistance caused by the growth of influenza $B$, that is, to co-operation occurring in the later stages of infection. Some eggs 
yielded influenza $\mathrm{B}$ alone; this finding is not strong evidence of independence when the ID 50 dose contains so few particles, because the inocula these eggs received may, by chance, have contained only influenza $B$.

\section{REFERENCES}

Bohnhoff, M., Drake, B. L. \& Mrrler, C. P. (1954). Effect of streptomycin on susceptibility of intestinal tract to experimental salmonella infection. Proc. Soc. exp. Biol., N.Y., 86, 132.

Donald, H. B. \& IsaACs, A. (1954). Counts of influenza virus particles. J. gen. Microbiol. 10, 457.

Dutron, A. A. C. (1955). The influence of the route of injection on lethal infections in mice. Brit. J. exp. Path. 36, 128.

KunKel, L. O. (1934). Tobacco and aucuba mosaic infections by single units of virus. Phytopathology, 24, 13.

LiU, O. C. \& Henle, W. (1951). Studies on host-virus interactions in the chick embryo-influenza virus system. V. Simultaneous serial passage of the agents of influenza $A$ and $B$ in relation to variations in the growth cycle of influenza $B$ virus. J. exp. Med. 94, 291.

LiU, O. C. \& Henle, W. (1953). Studies on host-virus interactions in the chick embryo-influenza virus system. VII. Data concerning the significance of infectivity titration end-points and the separation of clones at limiting dilutions. $J$. exp. Med. 97, 889.

Meyneld, G. G. (1955). Some factors affecting the resistance of mice to oral infection by Salmonella typhimurium. Proc. R. Soc. Med. 48, 916.

Meynell, G. G. \& Stocker, B. A. D. (1957). Some hypotheses on the aetiology of fatal infections in partially resistant hosts and their application to mice challenged with Salmonella paratyphi-B or Salmonella typhimurium by intraperitoneal injection. J. gen. Microbiol. 16, 38. 